\title{
Restricting the marketing of foods and non-alcoholic beverages to children in South Africa: are all nutrient profiling models the same?
}

\author{
Mariaan Wicks ${ }^{1 *}$, Hattie Wright ${ }^{2}$ and Edelweiss Wentzel-Viljoen ${ }^{1,3 *}$ \\ ${ }^{1}$ Centre of Excellence for Nutrition, Faculty of Health Sciences, North-West University, Potchefstroom, 2531, South Africa \\ ${ }^{2}$ Faculty of Science, Health, Education and Engineering, University of the Sunshine Coast, Maroochydore, QLD, 4558, Australia \\ ${ }^{3}$ Medical Research Council Research Unit for Hypertension and Cardiovascular Disease, North-West University, Potchefstroom, \\ 2531, South Africa
}

(Submitted 1 August 2016 - Final revision received 18 November 2016 - Accepted 18 November 2016)

\section{Abstract}

The WHO has called for governments to improve children's food environment by implementing restrictions on the marketing of 'unhealthy' foods to children. Nutrient profiling (NP) models are used to define 'unhealthy' foods and support child-directed food marketing regulations. The aim of the present study was to assess the suitability of the South African NP model (SANPM), developed and validated for health claim regulations, for child-directed food marketing regulations. The SANPM was compared with four NP models specifically developed for such regulations. A representative list of 197 foods was compiled by including all foods advertised on South African free-to-air television channels in 2014 and foods commonly consumed by South African children. The nutritional information of the foods was sourced from food packaging, company websites and a food composition table. Each individual food was classified by each of the five NP models. The percentage of foods that would be allowed according to the different NP models ranged from 6 to $45 \%$; the models also varied considerably with regard to the type of foods allowed for marketing to children. The majority of the pairwise comparisons between the NP models yielded $\kappa$ statistics $>0 \cdot 4$, indicating a moderate agreement between the models. An almost perfect pairwise agreement $(\kappa=0.948)$ existed between the SANPM and the UK Food Standards Agency model (United Kingdom Office of Communication nutrient profiling model), a model extensively tested and validated for such regulations. The SANPM is considered appropriate for child-directed food marketing regulations in South Africa.

\section{Key words: Nutrient profiling: Marketing of foods: Marketing regulation: Nutrition: Childhood obesity}

The prevalence of childhood obesity has increased dramatically during recent years and is no longer only prevalent in highincome countries $^{(1-4)}$. Recent data report that over the last decade the prevalence of overweight children in South Africa (both sexes combined) has increased from $10 \cdot 6$ to $18 \cdot 2 \%^{(5,6)}$. Childhood obesity has a large impact on the quality of life of children and poses major health and economic consequences for themselves, their families and the society as a whole ${ }^{(7)}$. The obesogenic environments that promote the consumption of foods high in fat, sugar and/or salt (HFSS) are thought to be a key driver in the global childhood obesity epidemic ${ }^{(8,9)}$. Unfortunately, because of rapid urbanisation and acculturation in numerous low-income and middle-income countries, many children are now raised in these obesogenic environments ${ }^{(8,10,11)}$

There is growing evidence that food marketing impacts food preferences of children, their consumption and purchasing requests to parents ${ }^{(12-15)}$. Child-directed food marketing is extensive, perhaps most prominent on television ${ }^{(16)}$, and research indicates that it primarily concern HFSS food products $^{(14,15,17,18)}$. The global increase in childhood obesity and the recognition that food marketing practices may influence the food choices of children have resulted in an increased public debate regarding the best course of action to improve the food environments of children. In 2010, the World Health Organization published a set of recommendations for the marketing of food and non-alcoholic beverages to children that was endorsed by the 63rd World Health Assembly (WHA 63.14) ${ }^{(19)}$. In 2016, the WHO released a report by the Commission on Ending Childhood Obesity, which notes with concern 'the failure of Member States to give significant attention to Resolution WHA 63.14' and 'requests that they address this issue ${ }^{(20)}$. Governments should therefore take leadership in combating childhood obesity by implementing a policy that aims to reduce the impact on children of marketing HFSS foods ${ }^{(3,20,21)}$. In order

Abbreviations: DoHSA, South African Department of Health nutrient profiling model for restricting food advertising to children; EMRO, WHO's Eastern Mediterranean Regional Office nutrient profiling model; HFSS, high in fat, sugar and/or salt; Ofcom, United Kingdom Office of Communication nutrient profiling model; REU, WHO's Regional Office for Europe nutrient profiling model; SAFBDG, South African Food-Based Dietary Guidelines; SANPM, South African nutrient profiling model.

* Corresponding authors: M. Wicks, fax +27 18299 2464, email 13009494@nwu.ac.za; E. Wentzel-Viljoen, fax +27 182992464 , email edelweiss-wentzelvijoen@nwu.ac.za 
for such a policy to be effectively implemented, a clear definition of the foods that should be restricted is required, unless the marketing of all foods is to be prohibited ${ }^{(22)}$. Nutrient profiling is defined as the science of classifying or ranking foods according to their nutritional composition for reasons related to preventing disease and promoting health' ${ }^{, 23,24)}$, and is suggested by the WHO to support child-directed food marketing restrictions ${ }^{(20)}$. Numerous nutrient profiling models with different aims have been developed, by academics, health organisations, national governments and food industries throughout the world. However, studies have indicated that the models classify foods differently ${ }^{(25-27)}$ and that a few have been thoroughly tested and validated ${ }^{(23)}$.

The manner in which nutrient profiling models have been constructed vary considerably. Some models use across-the-board nutrient criteria to classify foods in a limited amount of food categories (e.g. foods and drinks) ${ }^{(28,29)}$. Others use food categoryspecific nutrient thresholds for foods in many sub-categories (e.g. breakfast cereals, savoury snacks, cheeses, etc. $)^{(30,31)}$. Some classify foods solely on the basis of nutrients to limit ${ }^{(30,31)}$, whereas some also include elements such as dietary fibre to encourage consumption $^{(28,32,33)}$. It is recommended that policymakers seeking to use a nutrient profiling model for regulatory reasons should rather adapt an existing model from an authoritative source that has been validated, as it is more cost-effective and time saving ${ }^{(23,25)}$. There are now a large number of models available that are used or designed for child-directed food marketing restrictions. Previous studies also suggest that models designed for other applications, such as nutrient and/or health claim regulations, may also be suitable for this purpose ${ }^{(25,34)}$.

In South Africa, the South African nutrient profiling model (SANPM) is used to support the regulation of nutrient and/or health claims ${ }^{(33)}$. This model enjoys support from all stakeholders involved as it was thoroughly tested and validated before implementation into the regulation ${ }^{(35-37)}$. The South African National Department of Health, Directorate: Food Control, published a draft regulation aiming to restrict the marketing of all HFSS foods to children in $2014^{(33)}$. The draft regulation recommends using the South African Department of Health's (DoHSA) nutrient profiling model, which is an adapted model based on the SANPM. The SANPM was, however, developed and validated ${ }^{(35-37)}$ to assess whether food products are eligible to carry a nutrient and/or health claim in South Africa and not to regulate food marketing to children. Using the SANPM in the context of restricting the marketing of HFSS foods to children could be problematic as the model was never tested for this purpose. Therefore, this study aimed to explore how appropriate the SANPM is as a food classification tool for regulating the marketing of foods to children in South Africa.

\section{Methods}

The SANPM was compared with four existing, non-industry nutrient profiling models that were designed by national government departments, academic research groups and authoritative organisations to restrict the marketing of HFSS foods to children. The nutrient profiling models were compared to determine whether the models agree on (a) the percentage of foods permitted (overall strictness) and (b) the type of foods permitted for child-directed food marketing.

\section{The nutrient profiling models used for comparison}

In total, five nutrient profiling models were identified and included for comparison (Box 1).

Table 1 describes the characteristics of the above-mentioned nutrient profiling models. Energy, SFA, sugar (total or added) and Na/salt were used by all five models to classify foods. Total sugar refers to the sum of all intrinsic (lactose, fructose and galactose) and added sugars (monosaccharides and disaccharides), and added sugar refers to any sugar added to food by manufacturers, cooks or consumers during processing or preparation. A non-nutritive sweetener is a food additive (other than a monosaccharide or disaccharide sugar), of which one serving of $5 \mathrm{~g}$ provides $\leq 8 \mathrm{~kJ}(1.9 \mathrm{kcal})$ and a sweet taste equivalent to $5 \mathrm{~g}$ of sucrose $\mathrm{e}^{(30,33)}$.

Nutrient criteria algorithms were developed in Microsoft Excel 2013 according to the food classification criteria of the included nutrient profiling models. Each food item was individually classified, according to these nutrient criteria.

\section{Development of a representative food list}

Previous studies indicate that the majority of food advertisements on television are of savoury snacks, confectionery, sugarsweetened beverages and fast-food meals ${ }^{(14,15,17,18)}$. Studies also indicate that nutrient profiling models generally classify these foods as 'unhealthy', and that there is less agreement between models with regard to the classification of foods such as cheese, full-cream milk and non-nutritive, sweetened beverages ${ }^{(25)}$. In order to effectively compare how the included nutrient profiling models classified a variety of foods, a representative food list was developed as recommended by the literature ${ }^{(25)}$. The representative food list was developed is such a manner that it would allow the researchers to compare the classification of a variety of foods from various food groups. The representative food list included foods advertised on South African free-to-air television channels in 2014 and foods reported by recently published literature to be commonly consumed by South African children.

First, all advertised foods (child-directed and adult-directed) on free-to-air South African television channels (SABC 1, 2, 3 and eTV) in 2014 were included, because children are not only exposed to television advertisements aired during childdirected programming ${ }^{(43)}$. Television recordings on 4 weekdays (Monday to Thursday) and on Saturdays from 06.00 to 22.00 hours during the months of April, June, September and November of 2014 were used. These months were included in order to capture advertisement changes during the different seasons and holidays such as Easter and Christmas. The food advertisement list consisted of the names of the food products, names of the manufacturing companies, number of advertisements recorded during the sample time, presence of child actors in these advertisements and whether these advertisements were shown during child-directed programmes. A total of 1030 food advertisements were aired over the 4-month period. Advertisements were excluded if they were promoting 


\section{Box 1. The five nutrient profiling models included in the investigation}

South African nutrient profiling model (SANPM) ${ }^{(28,33)}$ : based on the model developed by the UK Food Standards Agency (FSA) and adapted by Food Standards Australia New Zealand for the regulation of health claims. In 2012, this model was adopted by the South African National Department of Health, Directorate: Food Control, to support the regulation of nutrient and/or health claims in South Africa. The validity of the model has been demonstrated ${ }^{(35-37)}$. This model is a scoring model that uses acrossthe-board nutrient criteria.

United Kingdom Office of Communication nutrient profiling model (Ofcom) ${ }^{(32)}$ : developed in 2005 by the UK FSA and adopted by Ofcom (the UK regulatory body for communications industries) in 2007 to support the regulation of food advertising during programmes aimed at children under the age of 16 years. This model has been extensively tested and validated $^{(38-39)}$ and is a scoring model that uses across-the-board nutrient criteria.

WHO's Regional Office for Europe nutrient profiling model $(R E U)^{(30)}$ : a nutrient profiling model developed in 2013 by the WHO regional office for Europe with the assistance and inputs of member states. The model is based on two existing models, the Norwegian model ${ }^{(40)}$ developed by the Norwegian government - adopted by industry with minor changes made for voluntary restrictions in Norway - and the model developed by the Danish Forum of Responsible Food Marketing Communications - endorsed by the Danish government for voluntary restrictions in Denmark ${ }^{(41)}$. The model was tested by European member states. The model is a threshold model that uses category-specific nutrient thresholds.

Table 1. Characteristics of the five nutrient profiling models

\begin{tabular}{|c|c|c|c|c|}
\hline Models & Type of model & Classification criteria & Nutrients to limit & Nutrients/elements to encourage \\
\hline SANPM & Scoring & Across-the-board & Energy, SFA, total sugar, salt/Na & Protein, fruits, vegetables, legumes and nuts \\
\hline Ofcom & Scoring & Across-the-board & Energy, SFA, total sugar, salt/Na & Protein, fruits, vegetables, legumes and nuts \\
\hline REU & Threshold & Food-category specific & $\begin{array}{l}\text { Energy, total fat, SFA, added sugar, salt/Na, } \\
\text { alcohol, NNS }\end{array}$ & None \\
\hline EMRO & Threshold & Food-category specific & $\begin{array}{l}\text { Energy, total fat, SFA, added sugar, salt/Na, } \\
\text { alcohol, NNS }\end{array}$ & None \\
\hline DoHSA & Scoring and threshold & Across-the-board & $\begin{array}{l}\text { Energy, total fat, SFA, total sugar, salt/Na, } \\
\text { NNS, added fluoride and aluminium }\end{array}$ & Protein, fruits, vegetables, legumes and nuts \\
\hline
\end{tabular}

SANPM, South African nutrient profiling model; Ofcom, United Kingdom Office of Communication nutrient profiling model; REU, WHO's Regional Office for Europe nutrient profiling model; NNS, non-nutritive sweeteners; EMRO, WHO's Eastern Mediterranean Regional Office nutrient profiling model; DoHSA, South African Department of Health nutrient profiling model for restricting food marketing to children.

(1) alcoholic beverages, coffee, tea or chewing gum; (2) retailers who provided a variety of products; (3) baby or toddler foods and milks; and (4) meal replacement supplements. This exclusion resulted in a total of 615 advertisements marketing 137 different food products.

Second, single food items and meals commonly consumed by South African children (3-18 years) were identified from the published literature ${ }^{(44-49)}$ and were included in the food list. This resulted in the identification of sixty additional food items.
Finally, a food list containing foods from various food groups was compiled. The food list consisted of 197 foods, of which 137 were foods advertised on South African free-to-air television channels and sixty were foods reported to be commonly consumed by South African children from the published literature.

\section{Collection of nutritional information of foods}

The majority of foods included in the food list were packaged foods. Nutritional information of these foods was sourced from 
the nutrition information panel indicated on the food items by using the George Institute Data Collection Application version $1.1^{(50)}$. Nutritional information of fast-food meals, restaurant meals and foods containing no nutrition information panel was sourced from the websites of companies. If no nutritional information was available on these particular webpages, the nutritional information of a similar food was sourced from the Condensed Food Composition Tables for South Africa ${ }^{(51)}$.

\section{Statistical analyses}

The proportion of foods allowed by each nutrient profiling model to be marketed to children was calculated, and the overall pairwise agreement between the models was assessed by using Cohen's $\kappa$ coefficient. Agreements were assessed as follows: 0.00-0.20 'slight', 0.21-0.40 'fair', 0.41-0.60 'moderate', 0.61-0.80 'substantial' and 0.81-1 'almost perfect' ${ }^{\text {(52). }}$.

The included foods were divided into food groups on the basis of the revised South African Food-Based Dietary Guidelines (SAFBDG) ${ }^{(53)}$. The main purpose of the SAFBDG is to guide the South African public to choose 'healthy' diets, which implies that these diets are adequate, meet all nutrient requirements and protect people against the development of diet-related, non-communicable diseases ${ }^{(53)}$. By keeping the main purpose of the SAFBDG ${ }^{(53)}$ in mind as well as the contribution of sugar-sweetened beverage consumption to added sugar intake ${ }^{(54)}$ and obesity ${ }^{(55)}$ of children, the following eight food groups were chosen: starchy foods (breads, grains, potatoes and cereals); vegetables, fruits and legumes; milk and dairy products; meat and eggs; fats and oils (margarines, cooking oils and peanut butter); composite dishes (foods composed of items from more than one category such as beef stew); sugar-sweetened beverages; and finally HFSS foods (foods that are not part of the SAFBDG for healthy eating such as sweets, confectionery and savoury snacks). For each type of food in the food groups listed above, the number of nutrient profiling models that would allow the food to be marketed to children was calculated.

\section{Results}

Of the 615 food advertisements captured, 125 (20\%) were aired during child-directed programmes and 269 (43.7\%) used child actors $^{(56)}$. The most frequently advertised foods were foods from the HFSS foods (51.5\%), composite dishes (14\%) and sugar-sweetened beverages (13.6\%) food groups. The majority of foods reported by literature to be frequently consumed by South African children were from the HFSS foods (27.84\%) and vegetable, fruits and legumes (20.59\%) food groups.

Fig. 1 illustrates the percentage of foods from each food group, which will be allowed for marketing to children when applying the five nutrient profiling models. Interestingly, the DoHSA model only allows foods from the starchy foods (35\%) and vegetable, fruit and legume (30\%) food groups to be marketed to children, whereas the SANPM allows selection of food from all the food groups to be marketed to children. The percentage of foods allowed for child-directed food marketing from the milk and dairy groups ranged from $0 \%$ (DoHSA) to

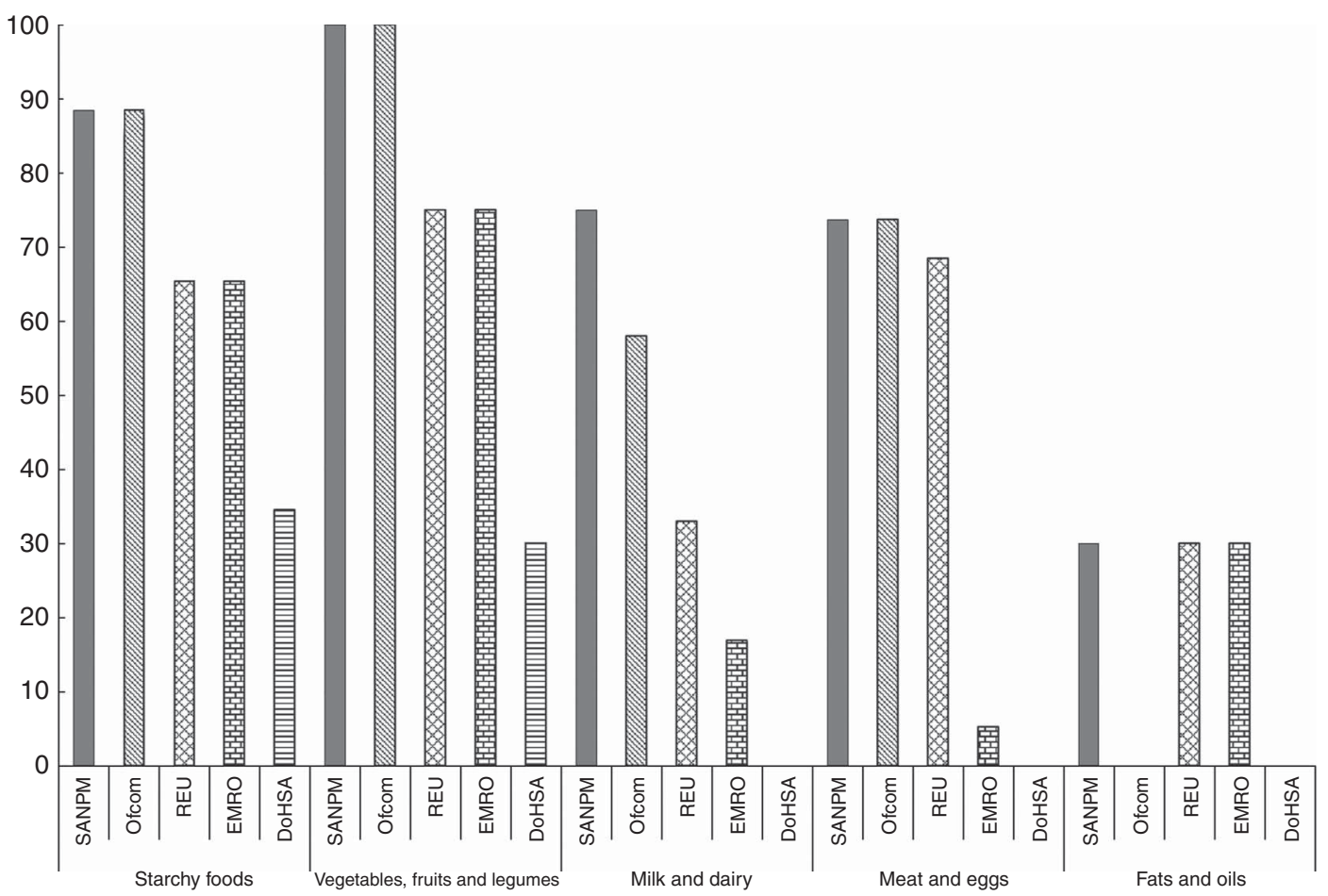

Fig. 1. The percentage of foods from different food groups allowed to be marketed to children according to each of the nutrient profiling models. SANPM, South African nutrient profiling model; Ofcom, United Kingdom Office of Communication nutrient profiling model; REU, WHO's Regional Office for Europe nutrient profiling model; EMRO, WHO's Eastern Mediterranean Regional Office nutrient profiling model; DoHSA, South African Department of Health nutrient profiling model for restricting food marketing to children. 
$75 \%$ (SANPM). The only models allowing foods from the HFSS foods and sugar-sweetened beverages food groups to be marketed to children were the SANPM (11\%) and United Kingdom Office of Communication nutrient profiling model (Ofcom) models (11\%, respectively).

Table 2 summarises the explanations for differences in food classification by the included nutrient profiling models. For example, bran flakes (breakfast cereal) was restricted for marketing by the WHO's Regional Office for Europe nutrient profiling model (REU) and the WHO's Eastern Mediterranean Regional Office nutrient profiling model (EMRO) models because of the high $\mathrm{Na}$ content of this specific food product.

Table 3 indicates that an almost perfect pairwise agreement was found between the SANPM and the Ofcom models, and a moderate agreement between SANPM, REU and EMRO models. The SANPM showed no agreement with the DoHSA model.

The DoHSA model, a combined nutrient profiling model, was the strictest. This model allows only $6 \%$ of foods on the food list to be marketed to children. The REU and EMRO models, which are category-specific nutrient threshold models, allow 32 and $20 \%$, respectively. The most lenient models were the two across-the-board scoring models - the SANPM model that allows $45 \%$ of the foods to be marketed to children and the Ofcom model that allows $42 \%$.

\section{Discussion}

The main findings of this study were that the included nutrient profiling models varied considerably with regard to their overall strictness, and that the DoHSA model is by far the strictest nutrient profiling model and the SANPM is the most lenient with regard to restricting the marketing of foods to children in South Africa. Other research studies have also compared nutrient profiling models for the purpose of restricting the marketing of 'unhealthy' foods to children ${ }^{(26,57,58)}$. The percentage of foods allowed to be marketed to children, according to Scarborough et $a l .{ }^{(57)}$, ranges from 2.4 to $39.88 \%$ and, according to Rayner et $a l .{ }^{(58)}$, from 4.76 to $39.88 \%$. A research study conducted by Brinsden \& Lobstein ${ }^{(26)}$ also compared nutrient profiling models but classified foods previously permitted to be advertised in the USA, and reported that the percentage of foods allowed to be marketed to children ranged from 14 to $49 \%$.

Another output in which the included nutrient profiling models differ, regardless of their overall strictness, is the type of foods the models would permit for marketing to children ${ }^{(25,57)}$. The nutrient profiling models generally agree that foods such as sweets, savoury snacks and sugar-sweetened beverages should be restricted for marketing to children. However, the models displayed little agreement on the type of foods that should be permitted for marketing to children as the classification of foods such as full-cream milk, cheese, sweetened yogurt, tinned peaches, breakfast cereals, etc. were undecided. Scarborough et $a l .{ }^{(57)}$ and Rayner et al. ${ }^{(58)}$ compared nutrient profiling models by using a representative list of foods that were advertised during child-directed programmes in 2008. Similar to our findings, the models included in their study agreed on foods that should not be allowed to be marketed to children (sugary and fatty foods, mostly snacks and confectionery); however, the models have shown little agreement on foods allowed for marketing. In contrast, the nutrient profiling models compared by Brinsden \& Lobstein $^{(26)}$ found little agreement on both foods permitted and not permitted to be marketed to children. Discrepancy in the findings was attributed to including nutrient profiling models developed by both governments and the food industry ${ }^{(26)}$. Government-led nutrient profiling models are significantly more restrictive than industry-led nutrient profiling models because of their stricter sugar and $\mathrm{Na} /$ salt criteria. In comparison to the findings of previous research articles, the SANPM is rather lenient when it is applied for restricting the marketing of HFSS foods to children. Rayner et al. ${ }^{(25)}$ defined a strict nutrient profiling model - a model that classifies most foods as 'unhealthy'. Thus, the SANPM could still be considered as a relatively strict model, even though certain foods from food groups generally considered to be 'unhealthy' (sugar-sweetened beverages and HFSS foods groups) were permitted for marketing to children. The DoHSA model is very strict and permits a few foods for marketing to children. The additional nutrient threshold criteria $^{(42)}$ of the DoHSA model were the main reason for its stringency.

Nutrient profiling models differ in both their strictness and the type of foods they would permit for marketing to children because of the differences in their respective structures. These differences include the nutrients used, the number of food categories the model contains, the type of model (acrossthe-board or category-specific) and the additional classification criteria. In this research article, the across-the-board nutrient profiling models (SANPM and Ofcom models) were found to be more lenient than the category-specific models (REU and EMRO models). This could be because of the fact that across-the-board scoring nutrient profiling models motivate the fact that certain food groups should be eaten more often than others by applying the same definition of 'unhealthy' to all food groups. This motivation, however, means that foods such as nonnutritive, sweetened beverages and certain fruit ices from the sugar-sweetened beverages and HFSS foods groups are permitted to be marketed to children by the SANPM and Ofcom models. This is in contrast with category-specific threshold models that motivate 'healthier' foods within a food group to be chosen more often by applying different definitions of 'unhealthy' to different food groups ${ }^{(59)}$. Category-specific nutrient profiling models also prohibit certain food groups such as sweets, confectionery, fruit juices and edible ices from being marketed to children irrespective of their nutrient content. This is because of the fact that these nutrient profiling models intend to motivate the public to rather choose 'healthier' foods from food groups proven to be essential components to 'healthy' diets ${ }^{(57)}$.

Nutrient profiling models are also now used by the food industry to re-formulate food products. However, concerns have been raised that in order to 'pass' some of the nutrient profiling models' classification criteria, certain foods that ordinarily would not 'pass' the nutrient profiling models' classification will now be developed ${ }^{(60)}$. Such foods include highly-processed food products with little or no nutritional value or foods artificially fortified with ingredients considered healthy. In order to prevent such foods from 'passing' the 
Table 2. Examples of foods of which the classification by nutrient profiling models differed

\begin{tabular}{|c|c|c|c|c|c|c|c|}
\hline \multirow[b]{2}{*}{ Food groups } & \multirow[b]{2}{*}{ Foods for which classification differed } & \multicolumn{5}{|c|}{ Nutrient profiling model } & \multirow[b]{2}{*}{ Reason why marketing to children is not permitted } \\
\hline & & SANPM & Ofcom & REU & EMRO & DoHSA & \\
\hline \multirow[t]{3}{*}{ Starchy foods } & Bran flakes & $\checkmark$ & $\checkmark$ & $\mathrm{x}$ & $x$ & $x$ & $\begin{array}{l}\text { Thresholds exceeded: } \\
\text { - Sodium: REU, EMRO and DoHSA } \\
\text { - Total sugar: DoHSA }\end{array}$ \\
\hline & Corn flakes & $\mathrm{x}$ & $\mathrm{x}$ & $\checkmark$ & $\checkmark$ & $\mathrm{x}$ & Score exceeded: SANPM, Ofcom and DoHSA \\
\hline & Oats & 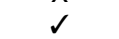 & $\checkmark$ & $\checkmark$ & $\checkmark$ & $\mathrm{x}$ & Threshold for total fat exceeded \\
\hline \multirow[t]{5}{*}{ Milk and dairy } & Cheese, Cheddar & $\checkmark$ & $x$ & $\mathrm{x}$ & $x$ & $\mathrm{x}$ & $\begin{array}{l}\text { Score exceeded: OfcomThresholds exceeded: } \\
\text { - Total fat: REU, EMRO and DoHSA } \\
\text { - SFA: REU, EMRO and DoHSA } \\
\text { - Sodium: REU, EMRO and DoHSA }\end{array}$ \\
\hline & Milk, full cream & $\checkmark$ & $\checkmark$ & $\mathrm{x}$ & $x$ & $\mathrm{x}$ & $\begin{array}{l}\text { Thresholds exceeded: } \\
\text { - Total fat: REU, EMRO and DoHSA } \\
\text { - SFA: DoHSA only }\end{array}$ \\
\hline & Milk, low fat & $\checkmark$ & $\checkmark$ & $\checkmark$ & $\checkmark$ & $x$ & $\begin{array}{l}\text { Threshold exceeded: } \\
\text { - Total fat: DoHSA } \\
\text { - SFA exceeded: DoHSA }\end{array}$ \\
\hline & Yogurt A, sweetened & $\checkmark$ & $\checkmark$ & $x$ & $x$ & $x$ & $\begin{array}{l}\text { Threshold exceeded: } \\
\text { - Added sugar: REU and EMRO } \\
\text { - Total sugar: DoHSA } \\
\text { - Sodium: EMRO }\end{array}$ \\
\hline & Yogurt B, sweetened (less added sugar) & $\checkmark$ & $\checkmark$ & $\checkmark$ & $x$ & $\mathrm{x}$ & $\begin{array}{l}\text { Thresholds exceeded: } \\
\text { - Total sugar: DoHSA } \\
\text { - Sodium: EMRO }\end{array}$ \\
\hline \multirow[t]{2}{*}{ Meat and eggs } & Chicken, meat and skin, roasted & $\checkmark$ & $\checkmark$ & $\checkmark$ & $x$ & $\mathrm{x}$ & $\begin{array}{l}\text { Threshold exceeded: } \\
\text { - Sodium: EMRO and DoHSA }\end{array}$ \\
\hline & Tuna in vegetable oil & $\checkmark$ & $\checkmark$ & $\checkmark$ & $x$ & $x$ & $\begin{array}{l}\text { Threshold exceeded: } \\
\text { - SFA: EMRO and DoHSA } \\
\text { - Sodium: DoHSA }\end{array}$ \\
\hline \multirow[t]{2}{*}{ Fats and oils } & Rapeseed oil & $\checkmark$ & $x$ & $\checkmark$ & $\checkmark$ & $\mathrm{x}$ & $\begin{array}{l}\text { Score exceeded: OfcomThreshold exceeded: } \\
\text { - Total fat: DoHSA } \\
\text { - SFA: DoHSA }\end{array}$ \\
\hline & Polyunsaturated medium fat spread ( $50 \%$ fat) & $\checkmark$ & $x$ & $\checkmark$ & $\checkmark$ & $x$ & $\begin{array}{l}\text { Score exceeded: OfcomThreshold exceeded: } \\
\text { - Total fat: DoHSA } \\
\text { - SFA: DoHSA }\end{array}$ \\
\hline \multirow{3}{*}{$\begin{array}{l}\text { Sugar-sweetened beverages } \\
\text { HFSS foods }\end{array}$} & Energy drink, non-nutritive sweetened & $\checkmark$ & $\checkmark$ & $\mathrm{x}$ & $\mathrm{x}$ & $\mathrm{x}$ & Threshold of non-nutritive sweeteners exceeded \\
\hline & Fruit ice, orange flavoured & $\checkmark$ & $\checkmark$ & $\mathrm{X}$ & $x$ & $x$ & $\begin{array}{l}\text { Food category not permitted: REU and EMROThreshold exceeded: } \\
\text { - Total sugar: DoHSA }\end{array}$ \\
\hline & Custard, vanilla flavoured & $\checkmark$ & $\checkmark$ & $\mathrm{x}$ & $x$ & $\mathrm{x}$ & $\begin{array}{l}\text { Food category not permitted: REU and EMROThreshold exceeded: } \\
\text { - Total sugar: DoHSA }\end{array}$ \\
\hline
\end{tabular}

SANPM, South African nutrient profiling model; Ofcom, United Kingdom Office of Communication nutrient profiling model; REU, WHO's Regional Office for Europe nutrient profiling model; EMRO, WHO's Eastern Mediterranean Regional Office nutrient profiling model; DoHSA, South African Department of Health nutrient profiling model for restricting food marketing to children. 
Table 3. Pairwise $k$ values calculated for the five models

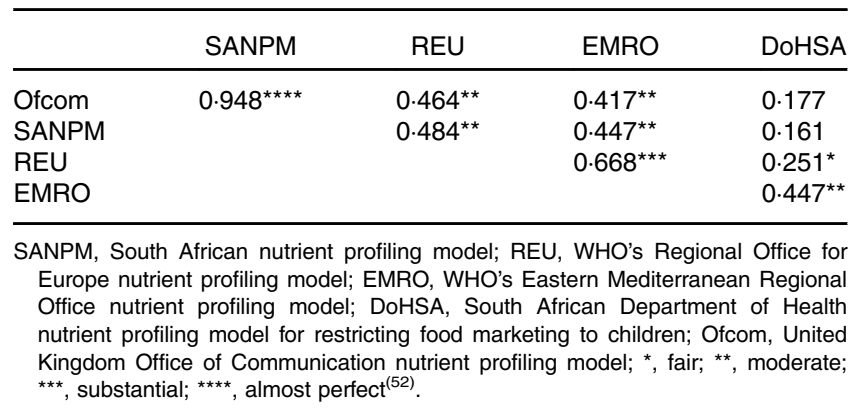

selected nutrient profiling model, policymakers are urged to adapt the chosen model by including additional classification criteria. Exclusions are thus made to the model or additional food categories are added. The SANPM was adapted by the South African Department of Health, Directorate: Food Control in order to create the proposed DoHSA model (Box 1). The proposed DoHSA model uses the SANPM as the first classification step followed by the UK Food Standards Agency front-of-pack traffic light labelling criteria for green $(\mathrm{low})^{(42)}$. The DoHSA model also excludes foods with the following food additives: non-nutritive sweeteners, fluoride, fructose and aluminium ${ }^{(42)}$. The non-nutritive sweetener criterion resulted in some of the foods permitted for marketing by the SANPM to be excluded by the DoHSA model. The use of non-nutritive sweeteners in the fight against childhood obesity is, however, uncertain, as the use of non-nutritive sweeteners is recommended by some ${ }^{(61,62)}$ while others are against it $^{(63)}$. The additional nutrient threshold criteria $^{(42)}$ of the DoHSA model mean that certain foods generally considered as essential components to a healthy diet, such as apples and low-fat milk, are classified as 'unhealthy'. It is, therefore, of utmost importance that policymakers are aware of the fact that adaptations made to nutrient profiling models could negatively affect the way in which they classify foods, which in return will impact the type of food marketing that children are exposed to. It can be concluded that the additional threshold criteria ${ }^{(42)}$ of the DoHSA model are very strict and allow a few foods to be marketed to children.

Nutrient profiling models do not only vary in the way that they have been constructed but also to the degree in which they have been validated ${ }^{(25)}$. Unfortunately, validity testing of nutrient profiling models is limited, and no gold standard for assessing the way in which nutrient profiling models classify foods exists ${ }^{(25)}$. The Ofcom model has been extensively tested $^{(26,57,58,64-66)}$ and validated ${ }^{(38,39)}$ for the purpose of regulating the marketing of foods to children. When comparing the SANPM with the Ofcom model, an almost perfect pairwise agreement was found (construct validity). This was, however, expected as the models are based on one another. Even so, there are still distinct differences between the models, although they have the same basic principles. The Ofcom model classifies foods into one of only two food categories (foods or beverages). The SANPM has an additional food category for cheese and processed cheese with a Ca content $>320 \mathrm{mg} / 100 \mathrm{~g}$, edible oils, edible oil spread, margarine and butter. Foods within this food category are allowed to obtain a higher score in comparison with that of foods in the other food categories because of the naturally high total energy, total fat and SFA content of these foods. This additional food category means that the percentage of foods permitted by the SANPM and Ofcom models from the milk and dairy (allowing 75 and 58\%, respectively) and fats and oils (allowing 30 and $0 \%$, respectively) groups varied considerably. A moderate pairwise agreement was found between the SANPM and the REU and EMRO models; these models also classify foods from the fats and oils food group similarly. No statistically significant level of agreement was found between the SANPM and the DoHSA models; the DoHSA model also prohibits any of the foods included in the milk and dairy and fats and oils food groups to be marketed to children. Available data indicate that the intake of milk and Ca by South African children is low due to the price of certain dairy products and lack of knowledge on the nutritional value of milk and dairy products. The accessibility and affordability of highly-processed packaged foods are increasing, and therefore it can be argued that the thresholds of the chosen nutrient profiling model be set appropriately so that certain cheeses and yogurts with little added sugar be allowed for marketing to children.

The comparison between the nutrient profiling models provided valuable information with regard to the suitability of the SANPM for child-directed food marketing regulations and highlighting the similarities and differences between the included models. The comparison also emphasised the importance of testing a nutrient profiling model before implementation into policy. However, the limitations of such a comparison should also be taken into consideration as more validity studies are needed to confirm the included nutrient profiling models' accuracy with regard to classifying or ranking the healthiness of foods. The WHO recommends that the nutrient profiling model being used to regulate the marketing of foods to children should align with the Food-Based Dietary Guidelines of the country in which it is intended for use ${ }^{(23)}$. It could, therefore, be argued that the nutrient profiling model used to regulate the marketing of foods to children in South Africa should permit 'healthy' foods within the food groups that the SAFBDG promote. The SANPM aligned well with the SAFBDG during the validity testing for nutrient and/or health claim regulatory use ${ }^{(35)}$. However, no validity testing of the DoHSA model has been conducted to date.

\section{Limitations}

The analysis reported in this article only included food advertisements broadcasted on free-to-air South African television channels and foods commonly consumed by the targeted population as identified from published literature. Foods marketed to children through other forms of marketing, such as radio broadcasts, product placements, product packaging and internet advertisements, were not included, and cross-continent food marketing through international television channels were also not included.

\section{Conclusion}

The nutrient profiling models included in this article vary considerably in both the total amount of foods and the type of 
foods allowed for marketing to children. The SANPM, already accepted and used by the South African food industry as the first screening process to determine a food product's eligibility for a nutrient and/or health claim, is appropriate as the first screening process for regulating the marketing of HFSS foods to children. The SANPM displays the best agreement with the Ofcom model and it permits certain dairy products such as lowfat yogurt to be marketed to children. However, further research is recommended to assess the validity of the SANPM and to develop an evidence-based framework to assist in the exclusion of certain highly processed foods that are included by the SANPM owing to limited nutritional values (such as energy drinks with non-nutritive sweeteners).

\section{Acknowledgements}

The authors thank Elizabeth Dunford for her gracious assistance and guidance with using the George Institute Data Collection Application, Willie Smit for developing the nutrient criteria algorithms in Microsoft Excel 2013, Janlie Delport for her endless precision and dedication while capturing the television food advertisements and Marike Cockeran for her assistance with the statistical analyses.

The authors received no financial support for this study.

The authors' contributions are as follows: M. W. wrote the statistical analysis plan, captured and analysed the data and drafted and revised the paper; E. W.-V. provided essential materials, participated in the statistical analysis plan and critically revised the paper for important intellectual content; H. W. analysed the data and critically revised the paper for important intellectual content

The authors declare that there are no conflicts of interest.

\section{References}

1. World Health Organization (2010) Population-Based Prevention Strategies for Childhood Obesity: Report of a WHO Forum and Technical Meeting, 15-17 December 2009. Geneva: WHO.

2. Ng M, Fleming T, Robinson M, et al. (2014) Global, regional, and national prevalence of overweight and obesity in children and adults during 1980-2013: a systematic analysis for the Global Burden of Disease Study 2013. Lancet 384, 766-781.

3. Lobstein T, Jackson-Leach R, Moodie ML, et al. (2015) Child and adolescent obesity: part of a bigger picture. Lancet $\mathbf{3 8 5}$, 2510-2520.

4. World Health Organization (2014) Facts and figures on childhood obesity. http://www.who.int/end-childhood-obesity/ facts/en/ (accessed December 2015).

5. Labadarios D, Swart R, Maunder E, et al. (2007) National Food Consumption Survey-Fortification Baseline South Africa, 2005. S Afr J Clin Nutr 21, 245-300.

6. Shisana O, Labadarios D, Rehle T, et al. (2013) South African National Health and Nutrition Examination Survey (SANHANES-1). Cape Town: HSRC Press.

7. Sonntag D, Ali S, Lehnert T, et al. (2015) Estimating the lifetime cost of childhood obesity in Germany: results of a Markov model. Pediatr Obes 10, 416-422.
8. Swinburn BA, Sacks G, Hall KD, et al. (2011) The global obesity pandemic: shaped by global drivers and local environments. Lancet 378, 804-814.

9. Boyland EJ, Nolan S, Kelly B, et al. (2016) Advertising as a cue to consume: a systematic review and meta-analysis of the effects of acute exposure to unhealthy food and nonalcoholic beverage advertising on intake in children and adults. $A m \mathrm{~J}$ Clin Nutr 103, 519-533.

10. Lobstein $\mathrm{T} \&$ \& Dibb S (2005) Evidence of a possible link between obesogenic food advertising and child overweight. Obes Rev 6, 203-208.

11. Hawkes C \& Lobstein T (2011) Regulating the commercial promotion of food to children: a survey of actions worldwide. Int J Pediatr Obes 6, 83-94.

12. McGinnis JM, Gootman JA \& Kraak VI (2006) Food marketing to children and youth: threat or opportunity? Committee on Food Marketing and the Diets of Children and Youth, Institute of Medicine. Washington, DC: The National Academies Press. http://www/nap.edu/catalog/115114.html (accessed June 2016).

13. Sadeghirad B, Duhaney T, Motaghipisheh S, et al. (2016) Influence of unhealthy food and beverage marketing on children's dietary intake and preference: a systematic review and meta-analysis of randomized trials. Obes Rev 17, 945-959.

14. Roberto CA, Baik J, Harris JL, et al. (2010) Influence of licensed characters on children's taste and snack preferences. Pediatrics 126, 88-93.

15. Boyland EJ \& Halford JC (2013) Television advertising and branding. Effects on eating behaviour and food preferences in children. Appetite 62, 236-241.

16. Cairns G, Angus K, Hastings G, et al. (2013) Systematic reviews of the evidence on the nature, extent and effects of food marketing to children. A retrospective summary. Appetite 62, 209-215

17. Kelly B, Hebden L, King L, et al. (2014) Children's exposure to food advertising on free-to-air television: an Asia-Pacific perspective. Health Promot Int 31, 144-152.

18. Zimmerman FJ \& Bell JF (2010) Associations of television content type and obesity in children. Am J Public Health 100, 334-340.

19. World Health Organization (2010) Set of Recommendations on the Marketing of Foods and Non-Alcoholic Beverages to Children. Geneva: WHO.

20. World Health Organization (2016) Report of the Commission on Ending Childhood Obesity. Geneva: WHO.

21. Hawkes C, Smith TG, Jewell J, et al. (2015) Smart food policies for obesity prevention. Lancet 385, 2410-2421.

22. Kelly B, King L, Baur L, et al. (2013) Monitoring food and non-alcoholic beverage promotions to children. Obes Rev $\mathbf{1 4}$ 59-69.

23. World Health Organization (2011) Guiding Principles and Framework Manual for the Development or Adaptation of Nutrient Profile Models, 1st ed. Geneva: WHO.

24. Rayner M, Scarborough P \& Stockley L (2004) Nutrient Profiles: Options for Definitions for Use in Relation to Food Promotion and Children's Diets. London. FSA. https://www. researchgate.net/profile/Mike_Rayner2/publication/267198176 (accessed June 2015).

25. Rayner M, Scarborough P \& Kaur A (2013) Nutrient profiling and the regulation of marketing to children. Possibilities and pitfalls. Appetite 62, 232-235.

26. Brinsden $\mathrm{H} \&$ Lobstein $\mathrm{T}$ (2013) Comparison of nutrient profiling schemes for restricting the marketing of food and drink to children. Pediatr Obes $\mathbf{8}, 325-337$.

27. Scarborough P, Payne C, Agu C, et al. (2013) How important is the choice of the nutrient profile model used to regulate 
broadcast advertising of foods to children? A comparison using a targeted data set. Eur J Clin Nutr 67, 815-820.

28. Food Standards Australia New Zealand (2013) Short Guide for Industry to the Nutrient Profiling Scoring Criterion in Standard 1.2.7 - Nutrition, Health and Related Claims. Australia New Zealand Food Standards Code. http://www.foodstandards. gov.au/industry/labelling/Documents/Short-guide-for-industryto-the-NPSC.pdf (accessed January 2015)

29. Rayner M, Scarborough P \& Lobstein T (2009) The UK Ofcom Nutrient Profiling Model. Defining 'healthy' and 'unhealthy' foods and drinks for TV advertising to children. https:// www.ndph.ox.ac.uk/bhfcpnp/about/publications-and-reports/ group-reports/uk-ofcom-nutrient-profile-model.pdf (accessed April 2014)

30. World Health Organization (2015) WHO Regional Office for Europe nutrient profile model. http://www.euro.who. int/_data/assets/pdf_file/0005/270716/Europe-nutrient-profilemodel-2015-en.pdf?ua=1 (accessed March 2015).

31. World Health Organization (2015) Consultation on Development of a Draft Regional Nutrient Profiling Module. Cairo: World Health Organization Regional Office for the Eastern Mediterranean.

32. United Kingdom Food Standards Agency (2011) Nutrient Profiling Technical Guidance: Food Standards Agency, United Kingdom Department of Health. https://www.food.gov.uk/ sites/default/files/multimedia/pdfs/techguidenutprofiling.pdf (accessed February 2015).

33. South African Department of Health (2014) R. 429 Foodstuffs, Cosmetics and Disinfectants Act (54/1972): regulations relating to the labelling and advertising of foods: Amendment Pretoria. http://www.gpwonline.co.za/Gazettes/Gazettes/ 37695_29-5_Health.pdf (accessed January 2015).

34. Julia C, Kesse-Guyot E, Touvier M, et al. (2014) Application of the British Food Standards Agency nutrient profiling system in a French food composition database. Br J Nutr 112, 1699-1705.

35. Wicks M (2012) The validation of a suitable nutrient profiling model for South Africa, North-West University. https://repository. nwu.ac.za/handle/10394/9253 (accessed April 2016).

36. Lee SJ (2013) Using existing dietary data for evaluating the construct validity of a nutrient profiling model, North-West University. http://dspace.nwu.ac.za.nwulib.nwu.ac.za/handle/ 10394/11743 (accessed April 2016).

37. Wentzel-Viljoen E, Jerling J, Vorster E, et al. (2012) Report: Testing and Software Development of a Nutrient Profiling Model for South Africa. Report to the National Department of Health, Directorate: Food Control, contract no. NDOH 17/2011-2012. Potchefstroom: North-West University.

38. Arambepola C, Scarborough P \& Rayner M (2008) Validating a nutrient profile model. Public Health Nutr 11, 371-378.

39. Azais-Braesco V, Goffi C \& Labouze E (2006) Nutrient profiling: comparison and critical analysis of existing systems. Public Health Nutr 9, 613-622.

40. South African Department of Health (2013) Appendix 1 to draft regulations. Foods and beverages that are considered unhealthy under these regulations [e-document]. http://www. eftasurv.int/media/notification-of-dtr/ (accessed January 2015).

41. Forum of Responsible Food Marketing for Children (2013) Code of responsible food marketing communication to children. Copenhagen: Forum of Responsible Food Marketing for Children. http://kodeksforfoedevarereklamer.di.dk/SiteCollection Documents/Foreningssites/kodeksforfoedevarereklamer.di.dk/ Downloadboks/Kodeks\%20eng\%20sep\%202008\%20samlet.pdf (accessed January 2015).

42. Food Standards Agency (editor) (2007) Front-of-pack Traffic Light Signpost Labelling Technical Guidance. London: Food
Standards Agency. https://www.gov.uk/government/uploads/ system/uploads/attachment_data/file/300886/2902158_FoP_ Nutrition_2014.pdf (accessed January 2015).

43. Mchiza ZJ, Temple NJ, Steyn NP, et al. (2013) Content analysis of television food advertisements aimed at adults and children in South Africa. Public Health Nutr 16, 2213-2220.

44. Tee L, Laubscher R, Botha C, et al. (2015) The intake and quality of breakfast consumption in adolescents attending public secondary schools in the North West province, South Africa. South Afr J Clin Nutr 28, 81-88.

45. Temple NJ, Steyn NP, Myburgh NG, et al. (2006) Food items consumed by students attending schools in different socioeconomic areas in Cape Town, South Africa. Nutrition 22, 252-258.

46. Steyn N, Maunder E, Labadarios D, et al. (2006) Foods and beverages that make significant contributions to macro- and micronutrient intakes of children in South Africa-do they meet the food-based dietary guidelines? South Afr J Clin Nutr 19, 66-76.

47. Napier C \& Hlambelo N (2014) Contribution of school lunchboxes to the daily food intake of adolescent girls in Durban. SAJCH 8, 59-63.

48. Nel JH \& Casey A (2003) Secondary data analyses of dietary surveys undertaken in South Africa to determine usual food consumption of the population. Public Health Nutr $\mathbf{6}$, 631-644.

49. Pedro TM, MacKeown JM \& Norris SA (2008) Variety and total number of food items recorded by a true longitudinal group of urban black South African children at five interceptions between 1995 and 2003: the Birth-to-Twenty (Bt20) Study. Public Health Nutr 11, 616-623.

50. The George Institute for Global Health (2014) The George Institute Data Collection App Version 1.1. https://itunes.apple.com/au/ app/data-collector/id545847554? mt=8 (accessed March 2015).

51. Wolmarans P, Danster N, Dalton A, et al. (2010) Condensed Food Composition Tables for South Africa, 1st ed. Cape Town: Medical Research Council.

52. Landis JR \& Koch GG (1977) The measurement of observer agreement for categorical data. Biometrics 33, 159-174.

53. Vorster HH, Badham J \& Venter C (2013) An introduction to the revised food-based dietary guidelines for South Africa. South Afr J Clin Nutr 26, S5-S12.

54. Feeley A \& Norris SA (2014) Added sugar and dietary sodium intake from purchased fast food, confectionery, sweetened beverages and snacks among Sowetan adolescents. SAJCH $\mathbf{8}$, 88-91.

55. Della Torre SB, Keller A, Depeyre JL, et al. (2015) Sugarsweetened beverages and obesity risk in children and adolescents: a systematic analysis on how methodological quality may influence conclusions. J Acad Nutr Diet 116, 638-659.

56. Delport JE (2015) Branding and cartoon character usage in food marketing to children: the South African picture. MSc Dietetics Mini-Dissertation, North-West University, South Africa.

57. Scarborough P, Payne C, Agu C, et al. (2013) How important is the choice of the nutrient profile model used to regulate broadcast advertising of foods to children? A comparison using a targeted data set. Eur J Clin Nutr 67, 815-820.

58. Rayner M, Mizdrak A, Logstrup S, et al. (2013) Reducing children's exposure to marketing of foods and drinks that are high in fat, salt or sugar: what would be the best nutrient profile model? British Heart Foundation Health Promotion Research Group, Department of Public Health, University of Oxford: European Heart Network. http://www.ehnheart.org/ component/downloads/downloads/1481 (accessed March 2016). 
59. Scarborough P, Arambepola C, Kaur A, et al. (2010) Should nutrient profile models be 'category specific' or 'acrossthe-board'? A comparison of the two systems using diets of British adults. Eur J Clin Nutr 64, 553-560.

60. Darmon N (2009) Letters to the Editor. Public Health Nutr 12, 1967-1968.

61. Miller PE \& Perez V (2014) Low-calorie sweeteners and body weight and composition: a meta-analysis of randomized controlled trials and prospective cohort studies. Am I Clin Nutr 100, 765-777.

62. Rogers P, Hogenkamp P, De Graaf C, et al. (2015) Does lowenergy sweetener consumption affect energy intake and body weight? A systematic review, including meta-analyses, of the evidence from human and animal studies. Int J Obes 40, 381-394.
63. Swithers SE (2015) Artificial sweeteners are not the answer to childhood obesity. Appetite 93, 85-90.

64. Jenkin G, Wilson N \& Hermanson N (2009) Identifying 'unhealthy' food advertising on television: a case study applying the UK Nutrient Profile model. Public Health Nutr 12, 614-623.

65. Romero-Fernandez MM, Royo-Bordonada MA \& RodríguezArtalejo F (2013) Evaluation of food and beverage television advertising during children's viewing time in Spain using the UK nutrient profile model. Public Health Nutr 16, 1314-1320.

66. Garsetti M, de Vries J, Smith M, et al. (2007) Nutrient profiling schemes: overview and comparative analysis. Eur J Clin Nutr 46, 15-28. 